\title{
Comparison between wettability gradients made on gold and on $\mathrm{Si} / \mathrm{SiO}_{2}$ substrates
}

\author{
S. Welin-Klintström *, M. Lestelius, B. Liedberg, P. Tengvall \\ Laboratory of Applied Physics, Linköping University, S-581 83 Linköping, Sweden
}

Received 7 July 1998; accepted 10 August 1998

\begin{abstract}
We have previously shown that wettability gradients on $\mathrm{Si} / \mathrm{SiO}_{2}$ can be used to analyze in detail the interactions of surfactants and proteins with the vast number of different surface properties that a gradient represents. We have also shown that the interactions of surfactants can be used to characterize the surface. In this report we discuss a new kind of wettability gradient that is composed from alkanethiols on gold. Surfactant and protein adsorption phenomena are investigated and compared with analogous experiments made on gradients prepared from chlorosilanes on $\mathrm{Si} / \mathrm{SiO}_{2}$ substrates. Surfactant adsorption studies were used to investigate the surface properties. Through their electrostatic interactions negatively charged groups on the surface could be detected and through their hydrophobic interactions defects in the surface layer resulting in hydrophobic groups could be detected. The alkanethiol gradient had at the extreme $\mathrm{OH}$-side an advancing contact angle to water between 30 and $40^{\circ}$. Still this surface had a lower adsorbed amount of fibrinogen compared to a (completely wetting) silica surface covered with negatively charged and uncharged silanol groups, indicating that the fibrinogen molecules also interacts electrostatically through their positively charged amino acid residues. This shows that the amount of fibrinogen adsorbed is not solely dependent on the surface hydrophilicity. (C) 1999 Elsevier Science B.V. All rights reserved.
\end{abstract}

Keywords: Wettability gradients; Alkanethiols; Gold; Chlorosilanes; $\mathrm{Si} / \mathrm{SiO}_{2}$; Proteins; Surfactants

\section{Introduction}

In our previous studies [1-6], we have mainly used the diffusion technique with chlorosilanes reacting with a $\mathrm{Si} / \mathrm{SiO}_{2}$ surface [1] to produce wettability gradients. The hydrophilic side is in this case composed of silanol groups having a point of zero charge close to $\mathrm{pH} 3$ [7]. At $\mathrm{pH}$ ca. 7 , which is commonly used in protein adsorption

\footnotetext{
* Corresponding author.
}

studies, the surface will have a negative charge contributing to the high surface energy. It was therefore interesting to compare earlier results from gradients made on $\mathrm{Si} / \mathrm{SiO}_{2}$ [3] with results from novel wettability gradients where the hydrophilic groups are composed of alcohol groups which will have no net charge at $\mathrm{pH}$ ca. 7 . This would give information about adsorption mechanism, i.e. whether it is dependent upon the substrate hydrophilicity and charge, or solely upon surface hydrophilicity. With the technique devel- 
oped by Liedberg and Tengvall $[8,9]$ it is possible to create gradients with a large number of chemical groups, among them alcohol groups. Their technique uses alkanethiols with different chemical head groups, where the thiols react strongly with the gold surface [10,11]. The different alkanethiols diffuse towards each other from glass filters and mix in a polysaccharide matrix. Simultaneously the thiol groups will bind to the gold surface. In this study, two alkanethiols were used, $\mathrm{HS}-\mathrm{C}_{15}-\mathrm{CH}_{3}$ and $\mathrm{HS}-\mathrm{C}_{16}-\mathrm{OH}$. Both these coatings has been shown to be stable over the interesting $\mathrm{pH}$ interval, see e.g. van der Vegte and Hadziiioannou [12]. In van der Vegte and Hadziiioannou [12] it is also shown that the alcoholgroup is uncharged between $\mathrm{pH} 2$ and 12, that is, no dissociation occurs.

\section{Experimental}

\subsection{Chemicals}

Phosphate buffered saline (PBS) $(10 \mathrm{mM})$ at pH 7 was used as buffer. Human fibrinogen was obtained from Kabi AB, Sweden. A stock solution was made by dissolving $4 \mathrm{mg} \mathrm{ml}^{-1}$ in PBSbuffer approximately $30 \mathrm{~min}$ before use. The experiments with surfactants were performed in MilliQ-water with a low content of organic material. $\mathrm{pH}$ was adjusted with $0.1 \mathrm{M} \mathrm{HCl}$ and $0.1 \mathrm{M}$ $\mathrm{NaOH}$, respectively. Homogenous pentaethyleneglycol mono n-dodecyl ether (BL-5SY) was obtained from Nikko, Tokyo, Japan. It will be denoted $\mathrm{C}_{12} \mathrm{E}_{5}$. Cetyltrimethylammonium bromide (CTAB) was obtained from Merck, Germany. Sodium dodecyl sulfate (SDS) was obtained from Sigma (L-4509). All results given are means of two to five experiments if not otherwise indicated.

\subsection{Wettability gradients on $\mathrm{Si} / \mathrm{SiO}_{2}$}

The wettability gradients on $\mathrm{Si} / \mathrm{SiO}_{2}$ were prepared as described by Elwing et al [1]. Shortly they were made from wafers of silicon (Okmetic OY, Finland) with a thermally grown oxide ca. 20 $\mathrm{nm})$. The wafers were cut into pieces $12.5 \times 70$ $\mathrm{mm}^{2}$. The pieces were rinsed by first heating them to $80^{\circ} \mathrm{C}$ in $\mathrm{H}_{2} \mathrm{O}: \mathrm{H}_{2} \mathrm{O}_{2}: \mathrm{NH}_{3}(5: 1: 1)$ for 5 min (TL1) and then rinsed with large amounts of water. This was followed by a second rinse where they were heated to $80^{\circ} \mathrm{C}$ in $\mathrm{H}_{2} \mathrm{O}: \mathrm{H}_{2} \mathrm{O}_{2}: \mathrm{HCl}(6: 1: 1)$ for 5 min (TL2) and then rinsed with large amounts of water [13]. This treatment gives a hydrophilic surface with an advancing contact angle for water that is less than $10^{\circ}$. The wettability gradients were then formed on these surfaces by diffusion of $0.1 \%$ dimethyldichlorosilane (Sigma) in trichloroethylene (Merck pA) up into a xylene (Merck pA) phase [1].

\subsection{Wettability gradients on gold}

The wettability gradients on gold were prepared as described by Liedberg and Tengvall [8]. Shortly they were made on gold substrates $(200 \mathrm{~nm}$ of gold deposited on pieces of silicon, $12.5 \times 70$ $\mathrm{mm}^{2}$ ). These gold substrates were then cleaned in TL1 and then left in laboratory air over night. The substrates were placed in a glass petri dish. A matrix was produced by swelling of $4.5 \mathrm{~g}$ of Sephadex LH-20 (Pharmacia Biotech, Sweden) in $15 \mathrm{~g}$ of ethanol $(95 \%$, Kemetyl, Sweden) for ca. 1 h. On this matrix two glass filters were placed with a distance of $25 \mathrm{~mm}$. Six hundred micro liters of $2 \mathrm{mM}$ alkanethiols $\mathrm{HS}-\mathrm{C}_{15}-\mathrm{CH}_{3}$ (Fluka) and $\mathrm{HS}-\mathrm{C}_{16}-\mathrm{OH}$ (a generous gift from Biacore AB, Uppsala, Sweden) in 95\% ethanol was added. The diffusion process was interrupted after $70 \mathrm{~h}$. The wettability gradients were then cleaned numerous times with water and ethanol in an ultrasonic bath for $10 \mathrm{~min}$ each time. The gradients were kept in water and used for experiments within $24 \mathrm{~h}$.

\subsection{Ellipsometry}

For the in situ measurements of surfactant and protein adsorption to wettability gradient surfaces an automated Rudolph Research null-ellipsometer 436 (New Jersey, US) with vertical sample orientation and a cuvette was used. For the measurements of refractive indices of the clean gold surface and the thickness of the alkanethiol layer an AutoEl III (Rudolph Research) was used. The 
instruments and the calculations of the adsorbed amounts have been described earlier [4].

\subsection{Contact angle measurements}

The advancing contact angles to water were measured using a Ramé-Hart goniometer 101 and MilliQ water with a low organic content, all in laboratory atmosphere with a temperature around $20^{\circ} \mathrm{C}[14]$.

\section{Results and discussion}

\subsection{Characterization of the wettability gradient on gold}

The characterization of the wettability gradient on gold using ellipsometry and contact angle measurements is shown in Fig. 1.

\subsubsection{Ellipsometry}

The refractive index of the clean gold substrate was measured before reaction with alkanethiols. The thickness of the alkanethiol layer on top of the gold substrate was calculated with an estimated refractive index of 1.5, see Fig. 1. From the dotted line that represents the thickness of the

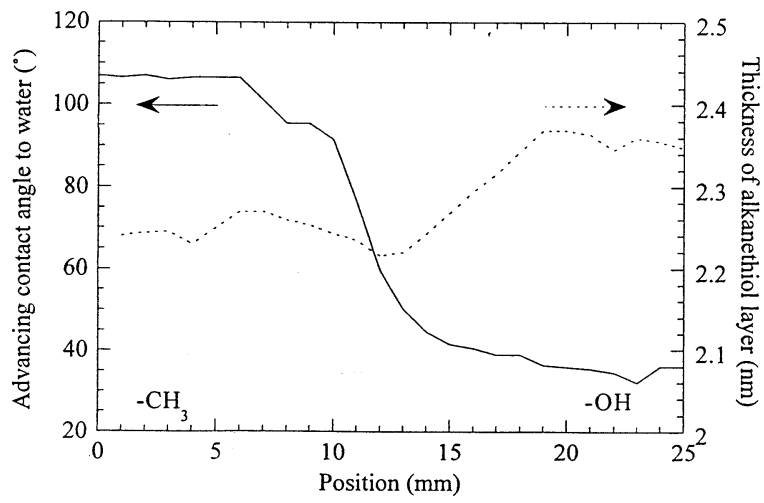

Fig. 1. Characterization of the wettability gradients made on gold substrates. The advancing contact angle to water (solid line) is indicated on the left axis. The thickness of the alkanethiol layer (dotted line) is indicated on the right axis. The hydrophobic end of the wettability gradient is to the left of the graph as indicated by $-\mathrm{CH}_{3}$ and the hydrophilic end is to the right as indicated by $-\mathrm{OH}$. alkanethiol layer it can be seen that the layer increases approximately $1.2 \AA$ going from the $\mathrm{CH}_{3}$-side to the $\mathrm{OH}$-side. This difference is in agreement with previous findings although the thickness is slightly higher than was observed earlier [8]. This could be attributed to differences in the optical constants of the gold surfaces. From the contact angle measurements, below, it can be seen that the length of the wettability gradient region is approximately $9 \mathrm{~mm}$ long. This region is only partly coinciding with the region were the thickness increases (ca. $6 \mathrm{~mm}$ long).

\subsubsection{Contact angle}

The advancing contact angle to water is on the hydrophobic side between 105 and $110^{\circ}$, which is in agreement with earlier studies [8]. On the hydrophilic side an advancing contact angle to water between 30 and $40^{\circ}$ is found. This is not in agreement with earlier findings in $[8,15]$ where advancing contact angles of $8-25^{\circ}$ are reported. In order to investigate this further, single component surfaces with $\mathrm{HS}-\mathrm{C}_{16}-\mathrm{OH}$ were prepared. These were rinsed and stored in different ways, but they all showed the same trend. Starting with an advancing contact angle to water around $20^{\circ}$ they all had contact angles between 30 and $45^{\circ}$ after $4-6 \mathrm{~h}$. After this time it was not possible to rinse the surfaces to restore the initially lower contact angles. This problem has earlier been observed and discussed in references [16,17]. One explanation is that the alcohol group will rotate in such a way that the outermost methylene groups will be 'visible' to the water droplet. A small portion of methylene groups mixed with alcohol groups will give an increase in the contact angle with water. Another explanation could be that the surface is contaminated with some organic material that can not be rinsed off with ultrasonification in ethanol or water. This finding needs to be further investigated, but it is beyond the scope of this work.

\subsection{Adsorption of surfactants}

3.2.1. $C_{12} E_{5}$

The adsorption of the nonionic surfactant $\mathrm{C}_{12} \mathrm{E}_{5}$ to wettability gradients on $\mathrm{Si} / \mathrm{SiO}{ }_{2}$ and gold 


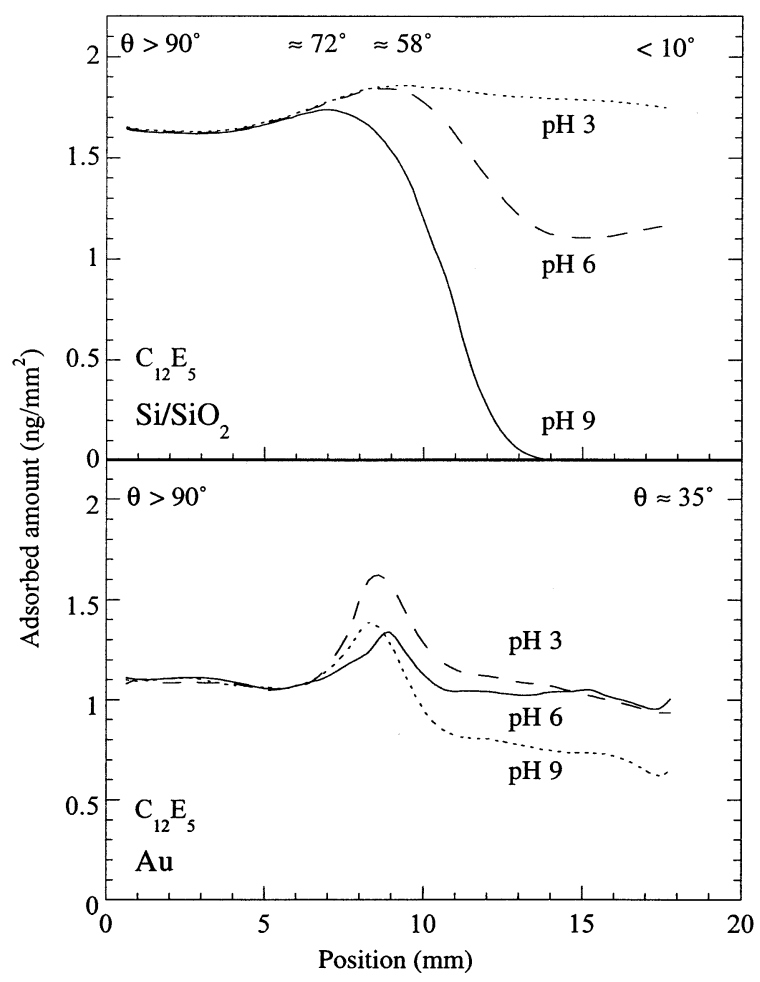

Fig. 2. Adsorption of nonionic surfactant $\mathrm{C}_{12} \mathrm{E}_{5}$ on wettability gradients made on $\mathrm{Si} / \mathrm{SiO}_{2}$ substrates (above) and gold substrates (below). The advancing contact angle to water $(\theta)$ is indicated at the top of each graph. The adsorption was made in MilliQ-water at three different $\mathrm{pH}$ as indicated. Observe that the distribution of the different wettability gradients formed on $\mathrm{Si} / \mathrm{SiO}_{2}$ and gold respectively is not the same.

substrates, respectively, is presented in Fig. 2. On the hydrophilic part of the wettability gradient made on $\mathrm{Si} / \mathrm{SiO}_{2}$ substrate there will be a number of deprotonated silanol groups giving a negative charge at $\mathrm{pH}>3$, the isoelectric point of $\mathrm{SiO}_{2}$. These charged groups and cations associated with them are believed to be the main reason why the nonionic surfactant adsorb less at $\mathrm{pH} 6$ and 9 compared to $\mathrm{pH} 3$ [4]. At $\mathrm{pH} 3$ and on a surface with only alcohol groups this nonionic surfactant will interact with its oxyethylenic chain and the $\mathrm{OH}$-groups. At the hydrophobic part of the gradient the hydrophobic parts of the surfactant will interact giving an adsorbed amount that is independent of $\mathrm{pH}$. At the hydrophilic side of the wettability gradient made on gold a decrease in adsorbed amount is observed at $\mathrm{pH}$ 9. We have presently no explanation to this behaviour. In the middle of the gradient region, there is an increase in adsorbed amount for the nonionic surfactant. This is an indication of that the film of alkanethiols is disturbed in that region making it possible for the hydrophobic tails of the surfactant to penetrate the alkane chains at defects, and adsorb. It has earlier been observed from infrared measurements that the chain cristallinity is reduced in the mixing region giving rise to a slightly a disordered assembly $[8,14]$

\subsection{2. $C T A B$}

The adsorption of the cationic surfactant CTAB to wettability gradients on gold and $\mathrm{Si}$ / $\mathrm{SiO}_{2}$ substrates respectively is presented in Fig. 3 . Small changes in the adsorbed amount of the

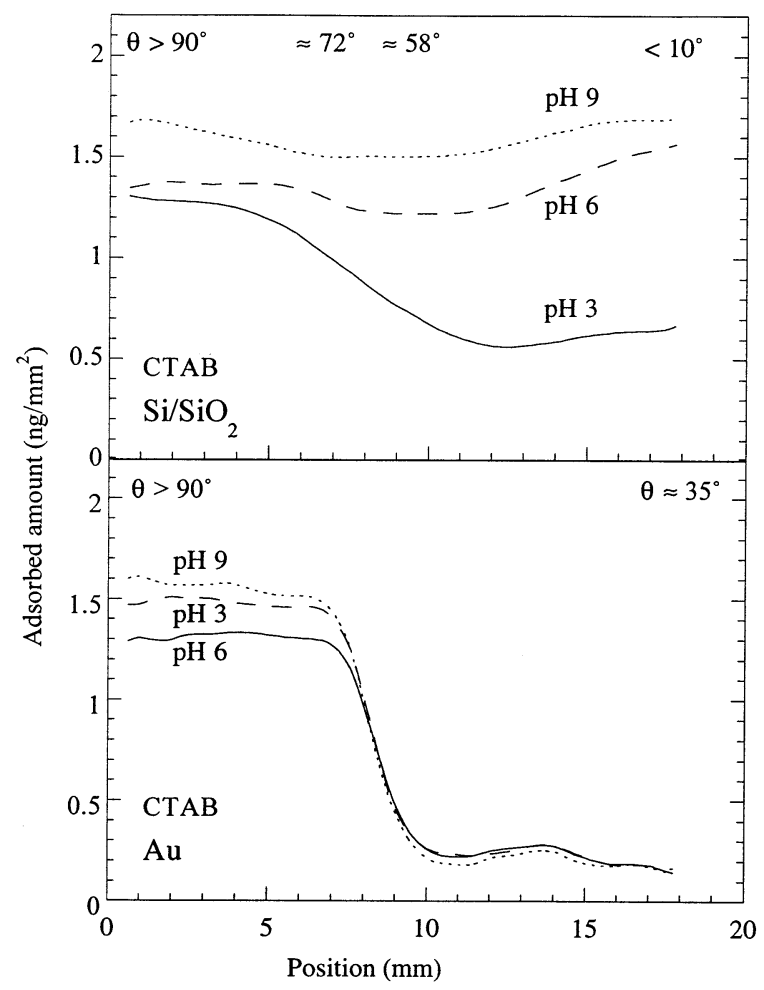

Fig. 3. Adsorption of cationic surfactant CTAB on wettability gradients made on $\mathrm{Si} / \mathrm{SiO}_{2}$ substrates (above) and gold substrates (below). The advancing contact angle to water $(\theta)$ is indicated at the top of each graph. The adsorption was made in MilliQ-water at three different $\mathrm{pHs}$ as indicated. 
cationic surfactant is seen at the hydrophobic part of the wettability gradients. On the hydrophilic side of the gradients made on $\mathrm{Si} / \mathrm{SiO}_{2}$ there is a significant change in adsorbed amount with $\mathrm{pH}$. This change can be explained with electrostatic interaction between the positively charged head group of CTAB and the changing amount of negatively charged silanol groups on the surface. On the wettability gradients made on gold the hydrophilic part adsorbs a low amount of cationic surfactant and the amount is not affected by changes in $\mathrm{pH}$. There are no negatively charged groups on the surface that could interact with the positively charged head of the surfactant and cause adsorption. The observed non-zero adsorption on the $\mathrm{OH}$-side could be explained if a small amount of defects are available for interaction with the hydrophobic tail of the surfactant.

\subsection{3. $S D S$}

The adsorption of the anionic surfactant SDS to wettability gradients on gold and $\mathrm{Si} / \mathrm{SiO}_{2}$ substrates respectively is presented in Fig. 4. No significant changes with $\mathrm{pH}$ could be observed. Therefore only results at pH 6 are shown. On the hydrophilic part of the wettability gradients made on $\mathrm{Si} / \mathrm{SiO}_{2}$ substrates no SDS adsorption is observed. This is expected since no hydrophobic groups exist on the surface, and the negatively charged groups on the surface will counteract adsorption of the negatively charged headgroup of the anionic surfactant. On the hydrophilic part of the wettability gradients made on gold substrates there is a small adsorbed amount. This may indicate just as in the CTAB experiments that a small amount of defects exist on the surface.

\subsection{Adsorption of fibrinogen}

The adsorption of fibrinogen to wettability gradients on $\mathrm{Si} / \mathrm{SiO}_{2}$ and gold substrates respectively is presented in Fig. 5 along with the surfactant induced desorption, see below. The adsorption of fibrinogen has earlier been shown to be dependent upon the hydrophobicity of the surface [2]. A remaining question was if there also is an interaction between the positively charged groups in the

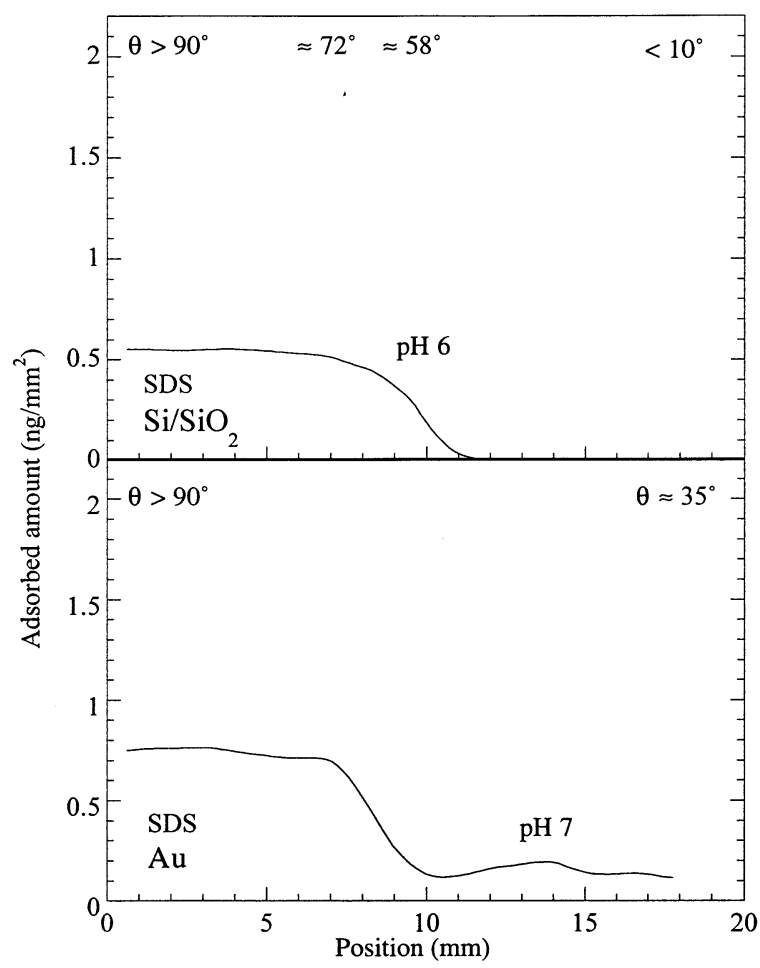

Fig. 4. Adsorption of anionic surfactant SDS on wettability gradients made on $\mathrm{Si} / \mathrm{SiO}_{2}$ substrates (above) and gold substrates (below). The advancing contact angle to water $(\theta)$ is indicated at the top of each graph. The adsorption was made in MilliQ-water at three different $\mathrm{pHs}$ as indicated.

fibrinogen molecule and the negatively charged groups of the surface. At $\mathrm{pH} 7$ approximately half of the silanol groups will be negatively charged despite that the point of zero charge is as low as pH 3 [18]. On the hydrophobic part of the wettability gradient made on gold or $\mathrm{Si} / \mathrm{SiO}_{2}$ substrates approximately the same adsorbed amount of fibrinogen is observed. On the hydrophilic side, on the contrary, a significant lower amount of fibrinogen is observed on the wettability gradients made on gold compared to the gradients made on $\mathrm{Si} / \mathrm{SiO}_{2}$. This is contradictory to the statement that fibrinogen adsorption is dependent solely on the hydrophobicity as the hydrophilic region of the gradient made on gold substrates has an advancing contact angle to water between 30 and $40^{\circ}$ compared to the hydrophilic region of the gradients made on $\mathrm{Si} / \mathrm{SiO}_{2}$ that has an advancing 
contact angle to water that is $<10^{\circ}$. This indicates that fibrinogen also interacts with the negatively charged silanol groups. If we assume that the adsorbed amount of fibrinogen on the hydrophilic part of the gradients made on gold depend to some extent on methylene groups, the adsorption on a $100 \% \mathrm{OH}$-surface would be even less than the observed amount. This agrees well with earlier findings on similar surfaces [16] and also to what is observed on surfaces composed of for example PEO (Polyethylene oxide) [19-21].

\subsection{Surfactant induced desorption of fibrinogen}

The surfactant induced desorption of a fibrinogen layer already adsorbed to wettability gradients on $\mathrm{Si} / \mathrm{SiO}_{2}$ and gold substrates respectively is presented in Fig. 5.

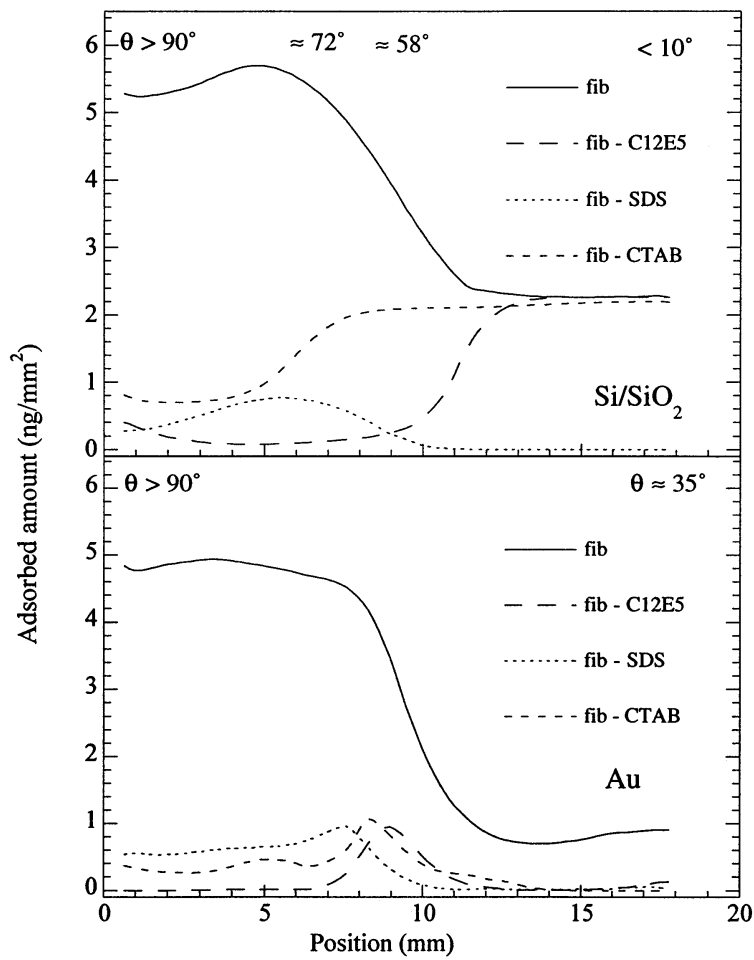

Fig. 5. Adsorption of fibrinogen and surfactant induces desorption on a previously adsorbed fibrinogen layer on wettability gradients made on $\mathrm{Si} / \mathrm{SiO}_{2}$ substrates (above) and gold substrates (below). The advancing contact angle to water $(\theta)$ is indicated at the top of each graph. The adsorption was made in PBS-buffer at $\mathrm{pH} 7$.
3.4.1. $C_{12} E_{5}$

On the hydrophobic part of the gradients made on both gold and $\mathrm{Si} / \mathrm{SiO}_{2}$ substrates respectively, the nonionic surfactant will desorb the layer of adsorbed fibrinogen. In the gradient region there is in both cases a region were not all fibrinogen can be removed. In the hydrophilic region there is a significant difference between the two kinds of wettability gradients. On the hydrophilic surface made on $\mathrm{Si} / \mathrm{SiO}_{2}$ substrates the nonionic surfactant can not desorb anything of the adsorbed layer of fibrinogen. This should be compared with the result on the hydrophilic surface made on gold substrates, which is built up by alkanethiols giving a surface with $\mathrm{OH}$-groups and probably some exposed methylene groups. In that case the already smaller amount of adsorbed fibrinogen is easily desorbed by the nonionic surfactant. This is an indication that the fibrinogen layer on the hydrophilic surface composed of negatively charged and uncharged silanol groups interact through its positively charged amino acid residues.

\subsection{2. $C T A B$}

In the gradient region and on the hydrophilic part of the wettability gradients made on $\mathrm{Si} / \mathrm{SiO}_{2}$ substrates CTAB desorbs only a fraction of the adsorbed fibrinogen. On the contrary CTAB can dissolve all adsorbed fibrinogen from the hydrophilic part of the wettability gradients made on gold substrates. This indicates that the fibrinogen layer interacts weakly with this hydrophilic surface. In the gradient region CTAB can not desorb all adsorbed fibrinogen indicating that the fibrinogen molecules in this region interacts better with the surface than it does on the hydrophilic side and on the hydrophobic side. It has been proposed that this depends on the possibility of fibrinogen to interact with hydrophobic, hydrophilic and negatively charged groups on the surface [3].

\subsection{3. $S D S$}

The anionic surfactant SDS can desorb the adsorbed layer of fibrinogen completely at the hydrophilic side of both kinds of wettability gradients. On the hydrophobic side almost all 
fibrinogen is desorbed in both cases. In the gradient region there is an increased amount of fibrinogen left after the desorption. This could be explained in the same way as above assuming that the same fibrinogen molecule can interact with different surface groups.

\section{Conclusions}

We have shown that the wettability gradient method is a versatile method to study protein and surfactant interactions with surfaces with different properties. In this paper we use a newly developed method that makes use of alkanethiols reacting with gold substrates. The alkanethiols may have a variety of headgroups and the reaction with gold is very strong. We show in this paper that surfactants can detect disturbances in the normally very dense surface layer. The earlier observed low protein adsorption on surfaces composed of alkanethiols with alcohol end groups was confirmed. It was also shown that the hydrophilic part of the wettability gradients made on gold substrates was not only composed of $\mathrm{OH}$-groups. The increased advancing contact angle to water and the adsorption of cationic and anionic surfactant indicates a small amount of exposed methylene groups. An interesting possibility for the future is to use gradients of ethylene oxide chains of different length to study similar phenomena.

\section{Acknowledgements}

This research was supported by grants from the Swedish Research Council for Engineering Science (TFR) and the Swedish Biomaterials Consor- tium with grants from the Swedish Foundation for Strategic Research (SSF).

\section{References}

[1] H. Elwing, S. Welin, A. Askendal, U. Nilsson, I. Lundström, J. Coll. Int. Science 119 (1987) 203.

[2] H. Elwing, S. Welin, A. Askendal, I. Lundström, J. Coll. Int. Science 123 (1988) 306.

[3] S. Welin-Klintström, A. Askendal, H. Elwing, J. Coll. Int. Science 158 (1993) 188.

[4] S. Welin-Klintström, R. Jansson, H. Elwing, J. Coll. Int. Science 157 (1993) 498.

[5] M.C. Wahlgren, T. Arnebrant, A. Askendal, S. WelinKlintström, Colloids Surf. A 70 (1993) 151.

[6] M.C. Wahlgren, S. Welin-Klintström, T. Arnebrant, A. Askendal, H. Elwing, Colloids Surf. B 4 (1995) 23.

[7] R.K. Iler 'The Chemistry of Silica', Wiley, New York (1979)

[8] B. Liedberg, P. Tengvall, Langmuir 11 (1995) 3821.

[9] B. Liedberg, M. Wirde, Y.-T. Tao, P. Tengvall, U. Gelius, Langmuir 13 (1997) 5329.

[10] R.G. Nuzzo, F.A. Fusco, D.L. Allara, J. Am. Chem. Soc. 109 (1987) 2358.

[11] P.E. Laibinis, G.M. Whitesides, D.L. Allara, Y.-T. Tao, A.N. Parikh, R.G. Nuzzo, J. Am. Chem. Soc. 113 (1991) 7152.

[12] E.W. van der Vegte, G. Hadziioannou, Langmuir 13 (1997) 4357.

[13] W. Kern, D.A. Puotinen, RCA Rev. 31 (1970) 187.

[14] M. Lestelius, I. Engquist, P. Tengvall, M.K. Chaudhury, B. Liedberg, Colloids Surf, B, 15 (1999) 55-68.

[15] I. Engquist, I. Lundström, B. Liedberg, J. Phys. Chem. 99 (1995) 12257.

[16] M. Lestelius, B. Liedberg, P. Tengvall, Langmuir 13 (1997) 5900

[17] S.D. Evans, R. Sharma, A. Ulman, Langmuir 7 (1991) 156.

[18] L. Bousse, S. Mostarshed, B. van der Shoot, N.F. de Rooij, P. Gimmel, W. Göpel, J. Coll. Int. Science 147 (1991) 22.

[19] K.L. Prime, G.M. Whitesides, Science 252 (1991) 1164.

[20] P. Harder, M. Grunze, R. Dahint, G.M. Whitesides, P.E. Laibinis, J. Phys. Chem. B 102 (1998) 426.

[21] G.B. Sigal, M. Mrksich, G.M. Whitesides, J. Am. Chem. Soc 120 (1998) 3464. 